\title{
Investigation and Chemical Analysis of Iron Ore Deposit Sites and Its Application in Teaching the Concept of Mixtures in Basic Science
}

\author{
James, Igui Umoru Ugbe, Agioliwhu Ugbe \\ Department of Chemistry Cross River State College of Education, Akamkpa
}

\begin{abstract}
The purpose of the study was on the investigation and chemical analysis of iron ore deposit sites and its application in teaching the concept of mixtures in Basic Science. A total of 120 JSS III Basic Science students were involved in the study. This number was made up of 73 males and 47 females drawn from four secondary schools in Calabar Educational Zones in Cross River State, Nigeria. Three research hypotheses and three research questions were formulated to guide the study. The instruments used in gathering data for the study were Basic Science Achievement Test (BSAT) and Basic Science Retention Test (BSRT). A non-randomized pretest posttest control group design was adopted for the study. Kuder-Richardson formula 21 was used to establish the reliability of Basic Science Achievement Test (BSAT). The reliability coefficient of BSAT was 0.76 . Data collected were analyzed using descriptive statistics, Analysis of Covariance (ANCOVA) and Scheffe post hoc analysis was used to obtain direction of significance. From the findings, it was observed that the chemical component of iron ore was effective in teaching the concept of mixture in basic science. It was also observed that the iron ore has significant main effect on students' performance and retention in the concept of mixture in basic science. There was also significant difference in the performance of male and female students when taught the concept of mixtures using iron ores. Conclusion from the findings led to the recommendations that basic science teachers should explore the use of local resources materials within their immediate environment to teach various concepts in sciences and indeed basic science.
\end{abstract}

Keywords: Iron Ore, Mixtures, Retention, Gender, Chemical Analysis.

DOI: $10.7176 / \mathrm{JEP} / 10-23-05$

Publication date: August $31^{\text {st }} 2019$

\section{Introduction}

The relevance of science and technology to national aspirations and economy explains to a large extent the huge commitment and support which most nations make to scientific and technological development (Olagunju, 2000) (Iroegbu \& Ige, 2003). This is because one of the indices of global leadership is a nation's capacity to employ modern technologies to meet its national needs. According to Acquaye, (2009) apart from raising men's standard of living, science has today enabled developing nations to achieve their desire to match the advancements made in industrialized countries in their various areas. These include such areas as health, agriculture, shelter, communication, environment and many more. Modern development is no longer possible outside the framework of science and technology, hence the need to teach Basic Science effectively in schools.

Basic Science is a way to gather and organize information about the natural world. It is a systemized body of knowledge gained through experimentation, observation, ordered thinking and valued judgment. Science generally is a collection of facts about the natural world around us. Naturally in science classes, emphasis is laid strictly on practical exercise as bases for concretizing knowledge already gained in previous lessons.

The use of the environment in teaching had long been emphasized (either to develop poor knowledge on a concept yet to be taught or as a means of concretizing what has already been learned in a classroom situation). The environment which includes home, parks, school garden, streams, etc. could be used in the teaching of mixtures and their separation.

The entire environment is a mixture of several substances which could be grouped primarily as living and non-living components. The living component comprises materials such as wood, sand, air, water, dead organic matter, and in-organic matter in various forms of salts, ores and mineral deposits. The student's experiences in the environment in everyday life could be used in the teaching of mixtures and their separation.

On this ground the need to use iron ore deposits as a resource in teaching mixtures in Basic Science is in support of Eshiet (2001) that the environment provides a situation that helps learners to gain affective, psychomotor and cognitive domains.

Extensive use has been made of the rich ores of iron ore from Abakaliki in Ebonyi State, Itakpa ore deposit in Kogi State, Nkalagu ore deposit in Anambra State and Biase ore deposit in Cross River State in the areas of casting such as fire grates railings, hot-water pipes and in wrought form used in making iron nails, sheeting, ornamental work, horse-shoes and agricultural implements. It could also serve as a potential resource in the teaching of certain concepts in basic science curriculum of junior secondary schools. 
In the junior secondary school curriculum, basic science occupies a unique position. It serves as one of the prerequisite to the study of agricultural science (DM as well as integrated science (DM).

Basic science principally refers to the scientific disciplines of physics, chemistry, biology and mathematics as well as to their sub-disciplines. It gets a bit tricky with respect to sub-disciplines for instance computational chemistry or computational materials science, as they often interact with engineering disciplines like computer engineering, etc. the principal idea behind something being labeled as basic sciences is that study of basis science which leads to a better understanding of natural phenomena. It looks for knowledge and discovery of facts to enable one to understand an already existing phenomenon.

In basic science, a mixture is a material made up of two or more different substances which are mixed in a variable proportion. A mixture refers to the physical combination of two or more substances in which the identities are retained and are mixed in the form of solutions, suspensions and colloids.

Mixtures are one product of mechanically blending or mixing chemical substances such as elements and compounds without chemical bonding or other chemical change, so that each ingredient substance retains its own chemical properties and make up. Despites that, there are no chemical changes to its constituents, the physical properties of a mixture such as its melting point, may differ from those of the components. Some mixtures can be separated into their components by using physical (mechanical or thermal) means. Azeotropes are one kind of mixtures that usually pose considerable difficulties regarding the separation processes required to obtain their constituents.

The teaching of mixtures in basic sciences at the JSS in Nigeria needs to be properly handled. Creativity contributes to the nation economic development, hence the need for the students to be taught thoroughly if it is to meet the educational and economic development. Mixture in basic science cannot be taught effectively without the use of appropriate instructional materials (Ajayi, 2015).

Teaching aids which are educational inputs are vital to the teaching of basic science and any other science subject in the school curriculum. Waus (2002) was of the opinion that the use of teaching aids would make discovered facts glued firmly to the memory of student.

The present age of science and technology lays much emphasis on the teaching of basic science, stressing the importance of basic science teaching in advancement, Fafuwa (1986) remarked that whether we like it or not we are living in a world's culture and any country that overlooks this significant truth does so at its own peril. It was the application of new discoveries in science and technology that transformed the erstwhile backward societies to advanced states. The speed with which these new phenomena were disseminated and proliferated gave the western world a leeway to gaining a substantial scientific and technological hegemony to cover the rest of the world. It is almost impossible today to lead a full and satisfactory life without a little knowledge of basic science. Nigeria, like all other countries, gives premium to education of citizens because it is the bedrock of development. The present inadequacy and, in some serious situations near absence of teaching aids, laboratory equipment, reagents and chemicals are well known to us.

Ifeokor (2001) showed from empirical study that such essential facilities like chemicals, specimens, radio, television, stoves, and models are not available in schools. He further observed that even where some of these can be obtained, the teachers are not competent in using them. Thus, the past three decades has been devoted to educational reforms in Nigeria with emphasis changing from memorization of "facts" of science to inquiryoriented approach that facilitates the development of conceptual understanding and Meta cognitive capabilities in the learner (Nwoji, 2000).

This change is specially needed now that there is hardly any aspect of human life and conditions of living that science has not made some significant influence. On this background, the need to be resourceful, flexible and innovative in order to face the challenges posed by increasing knowledge in basic science is imperative.

Dareng (2000) opined that basic science teaching now shifts more emphasis to practical, exploratory and experimental work. Science is defined as a body of knowledge with human quest to understand natural phenomena and respond to challenges through processes by which the knowledge is testable and verifiable Eshiet (1996). There is therefore every reason for teachers and learners to explore the immediate environment especially in teaching science subject such as basic science.

In the words of Okebokola (1997), making science learner-friendly means processing or packaging science in a way that learners will find an encounter with the subject attractive enough to make them thirst for another encounter. He further said the students' lack of interest in science is seen as fewer students choose to study science subjects when compared to arts and social science subjects. Thus science, especially basic science should be taught in an exploratory manner to obtain result. Because as a child explores, he acquires the scientific skills and attitudes that will result in meaningful learning.

Salau (2003) suggested that the problem of poor performance in school work and in internal or public examinations seems to looms/larger and larger because basic science is still being taught at abstract level by some teachers. There are many target groups that can play important roles in demystifying basic science. Among them are government, parents, students and teachers. The role of government includes provision of teaching-learning 
facilities and a conducive environment for effective learning of science Okebokola (1997). Still it is becoming increasingly obvious that government alone cannot shoulder the whole burden of financing science education.

Odor and Azeke (2002) are of the opinion that teachers should not use these inadequacy or lack of equipment as an alibi to indulge in poor teaching. The use of local materials in making the learning of basic science delightful is stressed by Awotua-Efebo (2002). It is considered that if local materials are effectively used, it will motivate the learner depending on how the learner perceives and pays attention to the local materials used.

Learning resources therefore include anything which can be an object of stimulus to the students and an aid to the teacher. Inyang (1997), by this definition it includes building, staffing, equipment, ideas and materials. Awotua-Efebo (2002) further indicated that the entire world is a resource. Eshiet (1996) is of the opinion that the home should be used as a resource because the early years of the learner are mostly spent at home where various experiences are gained. The home also extends to the immediate environment of the learner.

Balogun (2005) advised that in developing learning and teaching materials, the use of learner's environment and locally available resource should be used in providing first hand science experience. By so doing, students will come to appreciate that science is not only studied for the purpose of passing examination, but also as prerequisite for further courses in which the basic knowledge of science is needed. This will be in line with the new curriculum which emphasizes the development of students' problem-solving skills, manipulative skills, scientific attitudes, interest and appreciation (FRN, 2014). Based on this, improvisation and substitution in science teaching in Nigeria became more urgent and relevant. Thus, innovation in science teaching-learning is normal and a continuous process.

\section{Statement of the problem}

The concept of mixtures and their separation has been an area of great interest in environmental science. The chemist views it in terms of mixtures of several substances in various concentrations.

Basic science as a science course is activity - oriented and the suggested method for teaching it which is guided - discovery method, is resource - based [NPE, 2014]. This suggests that the mastery of basic science concepts cannot be fully achieved without the use of learning materials will certainly result to poor achievement and lack of interest in the course. Thus, Madubum (2012) stresses that a professionally qualified science teacher no matter how will trained, would be unable to put his ideas into practice if the school setting lacks the equipment and materials necessary for him/her to translate his/her competence into reality.

Researchers like Nwosu (2001) and Aguisobo (2013) affirms that there are inadequate resources for the teaching of basic science in public secondary school in Nigeria. They further stated that where they are little resources at all, they are not usually in good condition, while those that are in good condition are not enough to go round those who need them. Thus, the need for basic science teachers to be highly creative and resourceful by using learning material within the local environment becomes imperative.

Effective and meaningful teaching and learning of scientific concepts like mixture and separation of mixture require active student involvement in the teaching - learning process through meaningful and relevant hands-onactivities.

There is deficiency in the teaching of basic science in Nigeria secondary schools and this could be traced to lack of effective teaching and learning resources in our classrooms Nwosu (2001). Also basic science teachers have not been able to utilize learning resources within the environment to enhance teaching of basic science, (Umoren, 20002).

Studies have shown that improvisation-sourcing, selection and deployment of relevant instructional elements of the teaching learning process in the absence or shortage of standard or accredited teaching learning materials can always help in filling the gap especially when the materials are drawn from the learners' local environment. (Eshiet, 2002).

It may imply that conventional materials and reagents used in teaching basic science may not have helped in enhancing student's academic performance and retention. Therefore it becomes inevitable to try out other learning resources that could enhance effective teaching and learning of basic science.

The problem of this study is how can students' performance and retention in basic science be enhanced? Will iron ore deposits also be effective in facilitating students' performance and retention in the concept of mixtures in basic science? This work seeks to provide an example of the utilization of local materials in the teaching of mixtures in basic science.

\section{Purpose of the study}

The purpose of this study is to investigate whether teaching the concept of mixture in basic science to junior secondary school students using iron ore mixtures as a teaching resource has advantage on their performance compared to conventional materials.

The study is designed to achieve the following specific objectives.

1. To compare the performance of male and female basic science students taught the concept of mixture using 
iron ore deposits and iron filling and sulphur

2. To determine the constituent and composition of iron ore mixtures in four deposit sites.

3. To compare the performance of students taught using iron ore mixtures and standard iron fillings and sulphur as teaching resources in basic science.

4. To compare the effects of using iron ore mixtures and standard iron fillings and sulphur as resource in teaching the concept of mixture on students retention in basic science.

\section{Research Questions}

In order to guide the study, the following research questions were raised in the study:

1. What is the mean performance scores of basic science students taught the concept of mixtures using iron ores and those taught using conventional iron filing and sulphur as resources?

2. What differences exists among the mean retention scores of basic science students taught the concept of mixture using iron ores and those taught using conventional iron filings and sulphur as resources?

3. What is the mean performance scores of male and female Basic Science students taught the concept mixture using iron ores and those taught using conventional materials and reagents as resources?

\section{Research Hypotheses}

The study tested the following null hypotheses at 0.05 level of significance

Ho1. There is no significant difference in the mean performance scores of basic science students taught the concept of mixture using iron ores and those taught using conventional iron filing and sulphur as resources.

Ho2. There is no significant difference in the mean retention scores of basic science students taught the concept of mixture using iron ores and those taught using standard conventional iron filing and sulphur as resources.

Ho3 There is no significant difference in the mean performance scores of male and female basic science students taught the concept of mixtures using iron ores and those taught using conventional materials and reagents as resources.

\section{Research Methods}

Research design

The research adopted a non-randomized pretest-posttest control-group design.

\section{Area of study}

The study was conducted in Calabar Educational Zone of Cross River State, namely Ikom, Calabar and Ogoja Educational Zones. Calabar Educational Zone covers schools from Calabar South up to central.

\section{Population}

The population was all the Junior Secondary III (JSSIII) Basic Science students in Calabar Educational Zone of Cross River State. This class was chosen because the students had registered Basic Science as a subject in their Junior Secondary School Examination with National Examination Council (NECO).

Also the concept of mixture had not been taught to JSS III students. A total of 1,000 students representing all JSS III basic science students in schools of Calabar Educational Zone of Cross River State made up of the population.

\section{Sample/sampling technique}

Purposive sampling technique was used to select schools from the target population. The criteria were:

i. Schools that are currently presenting candidates for the Junior Secondary School Certificate Examination (JSSCE).

ii. Schools that have teachers in basic science with at least three years teaching experience.

iii. Schools that have basic science laboratory

iv. Schools in which the concept of mixtures had not been taught.

Eight schools met the above criteria. A random sampling technique through the use of balloting was carried out to select four schools among those that met the above criteria. The four schools were randomly assigned to treatment and control groups. On the whole, one hundred and twenty students (120) made up the sample size of the study.

\section{Instruments and validation}

Two researchers made Basic Science Achievement Test (BSAT) and Basic Science Retention Test (BSRT) were the instruments used for the study. A total of (25) multiple choice items were constituted on the concept of mixtures for the achievement test in Basic Science and Retention Test. The instruments were faced and content validated 
by two basic science experts.

Reliability of the instruments were determined using Kuder-Richardson's formula-21. A reliability index of 0.76 was obtained. The test was used to determine the performance and retention of students in the concept using iron ore mixture and iron filings and sulphur as teaching resources.

\section{Research procedure}

The following procedure was followed for the administration of the instruments. Relevant permission was obtained from the school principals as well as the basic science teachers in each of the schools used for the study. Basic science teachers in each school formed the research assistants.

Pretest was administered prior to treatment to all the two groups and the results were used as covariate measures.

After one week, the concept mixtures using iron ores as a resource was taught by the research assistants to the experimental groups from a well-articulated and validated lesson package developed by the researcher. The control group was taught using standard iron filings and sulphur. The teaching was done for four weeks of double periods of basic science per week. One week later, posttest was administered to the two groups (experimental and control) for one hour using twenty five item test. Three weeks after the posttest had been given the retention test was administered which was a reshuffled version of Basic Science Achievement Test (Posttest).

\section{Method of data analysis}

The data collected were analyzed using descriptive statistics and analysis of covariance (ANCOVA) using pretest scores as covariates. The scheffe multiple comparison test was used for the post hoc analysis. All hypotheses were tested at 0.05 level of significance.

\section{Results and Discussion}

\section{Research questions}

The three research questions were answered using mean and standard deviation.

\section{Research Question One}

What is the mean performance scores of basic science students taught the concept of mixtures using iron ores and those taught using conventional iron filing and sulphur as resources?

Table 1: Mean and Standard Deviation Scores of Students Taught Using Iron Ores and those Taught Using Conventional Materials and Reagents

\begin{tabular}{|l|c|c|c|c|c|c|}
\hline \multicolumn{1}{|c|}{ Group } & N & \multicolumn{2}{c|}{ Pretest } & \multicolumn{2}{c|}{ Posttest } & \multirow{2}{*}{$\begin{array}{c}\text { Mean } \\
\text { Gain }\end{array}$} \\
\cline { 3 - 6 } & & $\overline{\mathbf{X}}$ & SD & $\overline{\mathbf{X}}$ & SD & 45.15 \\
Experimental & 62 & 24.66 & 7.98 & 69.81 & 5.67 & 45.15 \\
Control & 58 & 22.95 & 7.25 & 54.97 & 6.32 & 32.02 \\
Total & 120 & 23.83 & 7.65 & 62.63 & 9.54 & 38.80 \\
\hline
\end{tabular}

As shown in table 1, the mean gain (45.15) of the experimental group (students, taught using iron ores) is greater than the mean gain (32.02) of the control group (students taught using conventional materials and reagents). This indicates that students taught using iron ores as a resource performed better than their counterparts taught using conventional materials and reagents.

\section{Research Question Two}

What differences exists among the mean retention scores of basic science students taught the concept of mixture using iron ores and those taught using conventional iron filings and sulphur as resources?

Mean and standard deviation was used in answering this research question as presented in table 2.

Table 2: Mean and Standard Deviation Scores of Experimental and Control Group

\begin{tabular}{|c|c|c|c|c|c|c|}
\hline \multirow[t]{2}{*}{ Group } & \multirow[t]{2}{*}{$\mathbf{N}$} & \multicolumn{2}{|c|}{ Pretest } & \multicolumn{2}{|c|}{ Posttest } & \multirow{2}{*}{$\begin{array}{c}\text { Mean } \\
\text { Gain }\end{array}$} \\
\hline & & $\overline{\mathbf{X}}$ & SD & $\overline{\mathbf{X}}$ & SD & \\
\hline Experimental & 62 & 24.66 & 7.98 & 59.24 & 4.94 & 34.58 \\
\hline Control & 58 & 22.95 & 7.25 & 48.14 & 5.85 & 25.19 \\
\hline Total & 120 & 23.83 & 7.65 & 53.87 & 7.74 & 30.04 \\
\hline
\end{tabular}

Table 2 showed that the mean gain (34.58) of the experimental group is greater than the mean gain (25.19) of the control group. This indicate that students taught using iron ores as a resource retained better than their counterparts taught using conventional materials and reagents.

Research Question Three

What is the mean performance scores of male and female Basic Science students taught the concept mixture using 
iron ores and those using conventional materials and reagents as resources?

Mean and standard deviation was used in answering this research question as presented.

Table 3: Mean and Standard Deviation Scores of Experimental and Control Group Based on Gender

\begin{tabular}{|c|c|c|c|c|c|c|c|}
\hline \multirow[t]{2}{*}{ Group } & \multirow[t]{2}{*}{ Gender } & \multirow[t]{2}{*}{$\mathbf{N}$} & \multicolumn{2}{|c|}{ Pretest } & \multicolumn{2}{|c|}{ Posttest } & \multirow{2}{*}{$\begin{array}{l}\text { Mean } \\
\text { Gain }\end{array}$} \\
\hline & & & $\mathbf{X}$ & SD & $\overline{\mathbf{X}}$ & SD & \\
\hline \multirow[t]{2}{*}{ Experimental } & Male & 38 & 25.29 & 8.19 & 69.32 & 5.59 & 44.03 \\
\hline & Female & 24 & 23.67 & 7.70 & 70.58 & 5.85 & 46.91 \\
\hline \multirow[t]{2}{*}{ Control } & Male & 35 & 22.66 & 6.73 & 56.63 & 5.98 & 33.97 \\
\hline & Female & 23 & 23.39 & 8.10 & 52.43 & 6.09 & 29.04 \\
\hline \multirow[t]{2}{*}{ Total } & Male & 73 & 24.03 & 7.59 & 63.23 & 8.58 & 39.92 \\
\hline & Female & 47 & 23.83 & 7.82 & 61.70 & 10.91 & 37.67 \\
\hline
\end{tabular}

Table 3 showed that the mean gain (46.91) of female students in the experimental group was greater than the mean gain (44.03) of their male counterparts in the same group while in the control group, the mean gain (33.97) of male students was greater than the mean gain (29.04) of their female counterparts. On the, whole the table showed that the mean gain (39.92) of male students was greater than the mean gain (37.17) of their female counterparts.

\section{Testing of Research Hypotheses}

The following three (3) hypotheses were tested at 0.05 level of significance.

Hypothesis One: There is no significant difference in the mean performance scores of basic science students taught the concept of mixtures using iron ores and those taught using conventional materials and reagents as resources.

This hypothesis was tested using the results

Table 4: Covariance Analysis (ANCOVA) of Students' Pretest Performance Classified by Resource Materials with Pretest as Covariate

\begin{tabular}{|l|r|r|r|r|r|c|}
\hline Source & \multicolumn{1}{c|}{ Sum of Squares } & \multicolumn{1}{c|}{ Df } & Mean Square & \multicolumn{1}{c|}{ F } & \multicolumn{1}{c|}{ Sign. of F } & Decision \\
\hline Corrected Model & $6625.04^{\mathrm{a}}$ & 2 & 3312.52 & 92.00 & .000 & $*$ \\
\hline Intercept & 40957.91 & 1 & 40957.91 & 1137.50 & .000 & $*$ \\
\hline Pre-test & 24.78 & 1 & 24.78 & 0.69 & .409 & NS \\
\hline Resource Materials & 6426.97 & 1 & 6426.97 & 178.49 & .000 & $*$ \\
\hline Error & 4212.83 & 117 & 36.01 & & & \\
\hline Total & 481590.00 & 120 & & & & \\
\hline Corrected Total & 10837.87 & 119 & & & & \\
\hline
\end{tabular}

$*=$ significant at .05 level of significance

NS = Not significant at .05 level of significance

As shown in table 4, the calculated probability value (F-value) .000 of the main effect of resource materials is less than the declared Probability value (alpha level) .05. Therefore, the null hypothesis is rejected. This implies that there exist a significant difference in the mean performance scores of basic science students taught the concept of mixtures using iron ores and those taught using conventional materials and reagents as resources.

Hypothesis Two: There is no significant difference in the mean retention scores of basic science students taught the concept of mixture using iron ores and those taught using conventional materials and reagents as resources.

This hypothesis was tested using the results

Table 5: Covariance Analysis (ANCOVA) of Students' Retention Scores Classified by Resource Materials with Pretest as Covariates

\begin{tabular}{|l|r|r|r|r|r|c|}
\hline Source & Sum of Squares & Df & Mean Square & \multicolumn{1}{c|}{ F } & \multicolumn{1}{c|}{ Sign. of F } & Decision \\
\hline Corrected Model & $3706.71^{\mathrm{a}}$ & 2 & 1853.35 & 63.29 & .000 & $*$ \\
\hline Intercept & 30615.35 & 1 & 30615.35 & 1045.41 & .000 & $*$ \\
\hline Pre-test & 11.85 & 1 & 11.85 & 0.41 & .526 & NS \\
\hline Resource Materials & 3601.65 & 1 & 3601.65 & 122.98 & .000 & $*$ \\
\hline Error & 3426.42 & 117 & 29.29 & & & \\
\hline Total & 355435.00 & 120 & & & & \\
\hline Corrected Total & 7133.13 & 119 & & & & \\
\hline
\end{tabular}

$*=$ significant at .05 level of significance

$\mathrm{NS}=$ Not significant at .05 level of significance

As shown in table 5, the calculated F-value .000 of the main effect of resource materials was less than alpha level .05. Therefore, the null hypothesis is rejected. This implies that there exist a significant difference in the mean retention scores of basic science students taught the concept of mixture using iron ores and those taught 
using conventional materials and reagents as resources.

Hypothesis Three: There is no significant difference in the mean performance scores of male and female basic science students taught the concept of mixtures using iron ores and those taught using conventional materials and reagents as resources.

This hypothesis was tested using the results.

Table 6: Covariance Analysis (ANCOVA) of Students' Posttest Scores Classified by Gender with Pretest as Covariate

\begin{tabular}{|l|r|r|r|r|r|c|}
\hline Source & Sum of Squares & \multicolumn{1}{|c|}{ Df } & Mean Square & \multicolumn{1}{c|}{ F } & Sign. of F & Decision \\
\hline Corrected Model & $6902.543^{\mathrm{a}}$ & 4 & 172.64 & 50.43 & .000 & $*$ \\
\hline Intercept & 40152.18 & 1 & 40152.18 & 1173.35 & .000 & $*$ \\
\hline Pre-test & 34.54 & 1 & 34.54 & 1.01 & .317 & NS \\
\hline Resource Materials & 6640.76 & 1 & 6640.76 & 194.06 & .000 & $*$ \\
\hline Gender & 58.49 & 1 & 58.49 & 1.71 & .194 & $*$ \\
Resource Materials* Gender & 224.96 & 1 & 224.96 & 6.57 & .02 & $*$ \\
Error & 3935.32 & 115 & 34.22 & & & \\
\hline Total & 481590.00 & 120 & & & & \\
\hline Corrected Total & 10837.87 & 119 & & & & \\
\hline
\end{tabular}

$*=$ significant at .05 level of significance

$\mathrm{NS}=$ Not significant at .05 level of significance

As shown in table 6, the calculated probability value (F-value) .194 of gender was less than alpha level .05. Therefore, the null hypothesis was rejected. This implies that there exist a significant difference in the mean performance scores of male and female basic science students taught the concept of mixture using iron ores and those taught using conventional materials and reagents as resources.

\section{Discussion of Result}

The results of the research findings are discussed here to show the implication for teaching and learning of basic science.

1. Chemical components of iron ores.

2. Effect of resource materials on students' performance and retention in basic science.

3. Effect of gender on students' performance and retention in basic science.

\section{Chemical Components of Iron Ores}

Chemical analysis of the components of the iron ores showed that it was a mixture of elements and oxides in various concentrations or percentages. The constituent mixtures composed of $\mathrm{Na}_{2} \mathrm{O}, \mathrm{Caco}_{3}, \mathrm{ZnO}, \mathrm{Fe}_{2} \mathrm{O}_{3}, \mathrm{PbO}, \mathrm{S}$, $\mathrm{P}_{2} \mathrm{O}_{5}, \mathrm{CuO}, \mathrm{MnO}, \mathrm{MgO}, \mathrm{SiO}_{2}$ and $\mathrm{Al}_{2} \mathrm{O}_{3}$.

\section{Effect of Resource Materials on Student's Performance and Retention in Basic Science}

The primary aim of this study was to investigate whether teaching the concept of mixture in Basic science to JSSIII students in secondary schools using iron ores as a teaching resource had advantage on their performance and retention compared to conventional materials and reagents. The results of investigation as shown in table 4 indicated that, a significant difference was found to exist in the mean performance scores of Basic science students taught the concept of mixture using iron ores and those taught using conventional materials and Reagents as resources. Findings resulting from the testing of this hypothesis as presented in table 4 show that the resource material (Iron Ores) had a significant main effect of $\mathrm{P}<.05$. This is because the calculated probability value (PValue). 000 of the main effect was less than the declared probability value (178.49).

The results of the investigation as shown in table 5 indicated that a significant difference was found to exist in the mean retention scores of Basic science students taught the concept of mixtures using iron ores and those taught using conventional materials and Reagents as resources. Also, findings resulting from the testing of this hypothesis as presented in table 5 show that the calculated P-value. 000 of the main effect is less than the declared probability value (122.98). The above findings appeared consistent with those of Nwosu (2003), Obi (2000) and Ezeliora (2001). These studies pointed out that resources materials from the environment were effective in enhancing performance and retention in science, concrete objects provide concrete basis for conceptual thinking and thus facilitates better and proper understanding of Basic science concepts.

The research study corroborate with the work of Busari (2006) who posited that the concrete concepts in Science can be learnt using real and instant perspectives through manipulation of materials. Such instant processes like dissolution, distillation, expansion and measurement are observed. Concepts that have properties like refractive Index, Hardness, Conductivity, Viscosity, Pressure, Phototropism can be tested and observed when concrete concepts are taught empirically, the learners for instance are opportune to interact with objects, body specimen or chemicals using their senses of sight, smell, feel, hearing and tasting. Properties and other descriptive 
characteristics are easily recalled for use where there is a recurrence of similar or familiar or novel objects, specimen or chemicals. This form of interaction is what is termed as learning Science "doing".

Models and resource materials engender students' interest and facilitate performance and retention due to the nature and level of activities in the class. Ezeliora (2001).

This study is also in line with the works of Eshiet (1996) that the environment is the largest and most complex laboratory ever imagined. Natural man-made fixtures and field scientific activities are available everywhere in the environment. The entire environment is a mixture of several substances that can be used in teaching certain concepts in Science. The student's experiences in the environment in everyday life could be used in the teaching of mixtures in Basic science. The concept of prior knowledge in enhancing, promoting and motivating meaningful learning is easily applicable here. The students already know about the Local Kauwa (ore). This prior knowledge becomes a base upon which laboratory teaching and experimentation in the concept of mixtures could be leveled.

\section{Effect of Gender on Student's Performance and Retention in Basic science}

Another area of concern in this study was to investigate the effect of gender on student's performance and retention in the concept of mixtures in Basic science after being taught with iron ores and conventional materials and Reagents.

The results of investigation as shown in table 6 indicated a significant difference in the mean performance scores of male and female Basic science Students taught the concept of mixtures using iron ores and those taught using conventional materials and Reagents. As shown in the table, the calculated P-value .194 is less than the alpha level .05, also, the results of investigation as shown in table 6 indicated that there is a significant difference in the mean retention scores of male and female Basic science Students taught the concepts of mixture using iron ores and those taught using conventional materials and reagents.

This might be due to the fact that applying appropriate teaching resources through the use of iron ores can help both male and female students learn and remember facts, apply skill, comprehend concepts, analyze and synthesize principles which are cognitive objects of Basic science. Also, the enthusiasm exhibited by both male and female students who showed equal zeal when they were taught using iron ores may have led to equal performance of given tasks. This might be due to the fact that male and female students interact with each other freely in groups and these led to increasing the depth of understanding, enhancing, motivation, developing problem solving skills and generating greater involvement of both male female students with the concept.

The presence of a significant gender effect on the performance and retention in the concept of mixture in Basic science in this study may not be unconnected with the scientific awareness and literacy in the society which has gone a long way in changing some societal expectations as well as attitudes of the women folk. The outstanding performance of some prominent female Scientists, Medical officers and Engineers may have also served as great motivators for the female students in their study of Basic science. This may be so because any good resource material especially the use of iron ores adopted in the teaching of the concept of mixture in Basic science does not discriminate between males and females. This result implies that, both male and female students have equal capability of responding to any type of teaching resource used in Basic science and can adequately achieve equal level of performance in the concept of mixtures in Basic science.

The result is consistent with the research findings of Wanbugu and Changeiyo (2008) that, gender had a significant influence on student's performance in Basic science. They noted that every learner both male and female must be given the opportunity to display his/her manipulative ability as fully as possible, be he quick or slow, deep or superficial in thinking, once they are taught with the same resource materials. This is because good performance of students depends on his interest as well as the technique used by the teacher and the types of resource materials involved. This study is in line with the findings of Popoola (2010) that, a significant gender difference exists in the performance of male and female students in science and mathematics.

Also, the findings of Karademir and Ucak (2009) indicated that a significant difference was found among achievement scores of the female students in ability grouping classes, however, this was reverse for the male students. The significant difference in the academic achievement of male and female students is in line with previous studies carried out by Meziobi (2001) who concluded in her research on student's achievement on the basis of gender, that there was significant difference between the achievement levels of boys and girls in the learning of selected Science concepts

\section{Conclusion}

On the basis of the findings in the study, the following conclusions were drawn:

i. Iron ore deposits were a suitable mixture of chemical substances for use in teaching the concept of mixture.

ii. There existed significant differences of the performance of students taught with iron are as teaching resources a and those taught with iron filings and sulphur. 


\section{Recommendations}

Based on the results of the study, the following recommendations were made.

1. Basic science teachers should explore the use of iron ore to teach various concepts in Basic science

2. Seminars/workshops should be organized for Basic science teachers to appraise them with the utilization of resources like iron ore in the learning and teaching of Basic science,

\section{REFERENCES}

Acquaye, J. E. (2000). Integrated Science Programme: Constraints and Prospects in Nigeria schools. The Nigeria Teacher Education Today, 1, 2 :96-100.

Agusiobo, A. (2013). Winning students in science. A paper presented at the $28^{\text {th }}$ Annual Conference of Science Teachers Association of Nigeria, 17-22 August.

Ajayi, M. A \& Ogunyemi, Y. (2015). Effect of learning environment on students' academic achievement in Lagos State secondary schools. Unpublished ME thesis University of Nigeria.

Awotua-Efebo, (2002). Making the learning of science, technology and Mathematics (STM) delighted using local materials. A lead paper presented at the conference on teaching and learning science, technology and Mathematics (STM) for optimum benefit.

Balogun, T. A. (2005) Improvisation of School Science Teaching Equipment. Journal of Science Teachers Association of Nigeria. 2 (2): 36.

Busari, T. O. (2006) Teaching Secondary School Science. Lagos University of Lagos Press.

Dareng, M. K. (2000). Improvisation in Mathematics. A paper presented at Science Teachers Association of Nigeria National conference in Kano.

Eshiet, I. T. (1996). Improvisation in Science Teaching, Philosophy and Practice Abak. Belpot publishers.

Ezeliora, B. (2001). Women Human Rights and Education. A review of the Igbo Women Situation. Torch. Enugu 113: $38-42$.

Fafunwa, A. B. (1986). Integrated Primary science (six years primary project). Institute of Education. University of Ife, Ile-Ife Ibadan. Evans Publishers.

Ifeakor, S. J. (2001). Gender Differences and Achievement in Agricultural Science. A study of schools in Kwara State. Journal of Technical Education 6 (1): 148-153.

Inyang, N. E. U. \& Ekpenyong, H. E. (2000). Influence of Ability and Gender Grouping on Senior Secondary School Chemistry Students' Achievement on the concept of Redox Reactions. Journal of Science Teachers Association of Nigeria. 25 (1\&2): 36-42.

Karademir, C. A. \& Ucak. E. (2009). The Effect Between Class Ability Grouping on $7^{\text {th }}$ Grade Students' Academic Achievement on the Unit, "If There Were no Pressure" in Science and Technology Education. Eurasian Journal of Physics and Chemistry Education. 1(1): 32-44.

Maduaburn, M. P. (2012) Primary School Science Teaching in Nigeria. A need for re-appraisal. The Nigerian Teacher 1: 97-103.

Mezieobi, S. B. (2001). The Role of Cognitive Development in Mezirow's Transformational Learning Theory. Adult Education Quarterly, 55 (1): 60 - 68.

National Policy on Education, (2014). Nigeria. FMB Press..

Nwoji, A. (2000) Cost Reduction Strategies for Managing Resources in Education in Nigeria Beyond the year 2000. African Journal of Education, 1 (1): 10-15.

Nworgu, B. G. \& Ayogu, Z. U. (2000).Effect of Gender and School Location on Students' Achievement in Physics. $40^{\text {th }}$ Annual Conference Proceedings of Science Teachers' Association of Nigeria 23(2): $79-85$.

Nwosu, A. J. (2001). Students Task Involvement and Achievement in Process Oriented Science Activities. Science Education. 70: 61-72.

Obi, J. A. (2000) Attitudes of Male and Female Students towards Science. London: Oxford University Press.

Odor, I. P. \& Azeke, O. T. (2002). Beyond Current Practice of Improvisation in Schools. Journal of Science Teachers Association of Nigeria. 25(1): 29-35.

Okebukola, P.A.O. (1997. How to Make Science Learner Friendly. Science Teachers Association of Nigeria Newsletter. 4(1): 4-6.

Popoola, F. R. (2010). Opinions of Male and Female Students of Gender Differences in Mathematics Learning in Nigeria. International Journal of Research in Education. 2 (1): 107-116.

Salau, M. O. A (2003). Survey of the Qualification of Nigerian secondary School Science and Mathematics Teachers. Science Teachers Association of Nigeria. 7(1 \& 2): 37-45.

Umoren, G. (2002) Attitudes of Male and Female students towards Science. Journal of Science Teachers Association of Nigeria. 4 (2): 79-83.

Wambugu, F. W. \& Changeiywo, J. M. (2008) Effects of Mastery Learning Approach on Secondary School Students' Physics Achievement. Eurasian Journal of Mathematics, Science \& Technology Education, 4(3): $293-302$ 